\title{
AN INVESTIGATION OF THE EFFECT OF ELECTRODE GEOMETRY AND FREQUENCY OF POWER SUPPLY IN THE HOMOGENEITY OF DIELECTRIC BARRIER DISCHARGE IN AIR
}

\author{
${ }^{2}$ R.B. Tyata', , ${ }^{1}$ D. P. Subedi* \\ ${ }^{1}$ Department of Physics, Kathmandu University, Dhulikhel, Nepal \\ ${ }^{2}$ Department of Physics, Khwopa College, Dekocha-5, Bhaktapur, Nepal \\ *Corresponding author: deepaksubedi2001@ yahoo.com \\ Received 12 December, 2009; Revised 17 February, 2010
}

\begin{abstract}
An experimental investigation of dielectric barrier discharge (DBD) produced in air is reported in the present paper. The discharge was produced by applying 0-20 kV AC source at frequency $10-30 \mathrm{kHz}$. The main objective of the study was to investigate the dependence of the discharge homogeneity on the frequency of applied source and the geometry of the electrodes. For this propose, three different types of electrodes were used. The discharge was systematically investigated on an extended range of electrical parameters using high frequency digital oscilloscope. Non-thermal nature of the discharge was tested by the treatment of hydrophobic polymer surface by measuring the change in contact angle with water drops.
\end{abstract}

Key words: DBD, electrode geometry, contact angle measurement, surface treatment

\section{INTRODUCTION}

In the last few decades, non-equilibrium plasma under atmospheric pressure have been developed as an effective means for surface modification of polymers (Shenton et al., 2001 and Wakida et al., 1996). These plasmas possess unique features that have led to a number of important applications such as ozone production, pollution control, bio-treatment of microorganisms, thin film deposition, surface modification, UV or VUV generation, aerosol charging and electro-filtration (Kogelschatz et al., 1997, Tepper et al., 2000, Kogelschatz et al., 1999, Fridman et al., 2005 and Hammer et al., 1999). They are rapidly being popular due to their many advantages, such as having no need for expensive vacuum equipment, being low cost and simple systems, and easy to operate (McAdams et al., 2001 and Bogaerts et al., 2002).

Usually a DBD plasma consists of many micro-discharges (or filaments) of nanosecond or microsecond duration. Therefore, these types of discharges are less homogenous compared to the low pressure glow discharges. The homogeneity of the DBD is very desirable for industrial applications especially for surface treatment processes. Several attempts have been made to produce a homogenous and glow like discharge at atmospheric pressure. Power supplies of a wide range of frequencies from DC to microwave, RF or in a short pulse (Moon et al., 2004, Moisan et al., 1992, Park et al., 2001, Simor et al., 2002, Moon et al., 2006 and Napartovich et al., 2001) have been used to generate atmospheric plasmas. The characteristics of the discharges are controlled by the operating parameters such as : voltage, frequency, gap width, nature of materials of the reactor and nature and operating conditions like gas flow rate, temperature and moisture (Massines et al., 1998 and Jidenko et al., 2006). The present work is focused on studying the influence of electrode geometry and frequency of the applied AC source on the uniformity of the discharge in atmospheric air. 


\section{EXPERIMENTAL SETUP}

Three different types of electrode configurations namely, cylindrical, parallel plate and annular were used in our experiment. The schematic diagram of cylindrical electrode system of DBD is shown in Fig. 1. It consists of two brass electrodes surrounded by a glass layer of thickness $1 \mathrm{~mm}$. The gap between the two electrodes can be varied from $2 \mathrm{~mm}$ to $5 \mathrm{~mm}$. Similarly, the parallel plate electrode system of DBD is shown in Fig. 2. It also consists of brass electrode with glass as dielectric. Here the area of the space between the two electrodes is much larger than in the case of cylindrical electrode. Fig. 3 shows the annular electrode system with central brass electrode surrounded by glass tube placed co-axially with the outer electrode wrapped around another glass tube with a clearance of $3 \mathrm{~mm}$ between them.

The discharge current and voltage across the gap are measured by Tektronix TDS 2002. The frequency of the power supply is varied in range $15 \mathrm{kHz}$ to $22 \mathrm{kHz}$. The signal from the oscilloscope is transmitted to personal computer. The images of the discharge were captured by a digital camera.

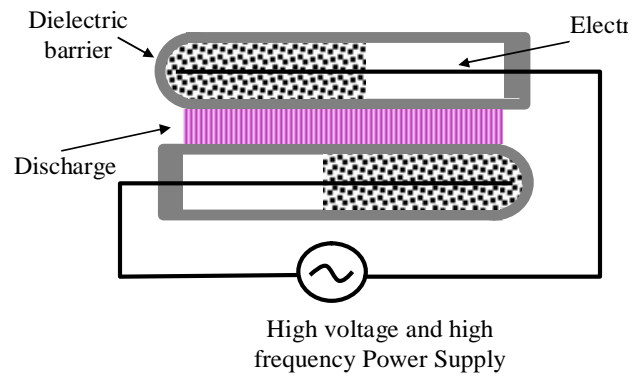

Fig.1 Schematic diagram of cylindrical

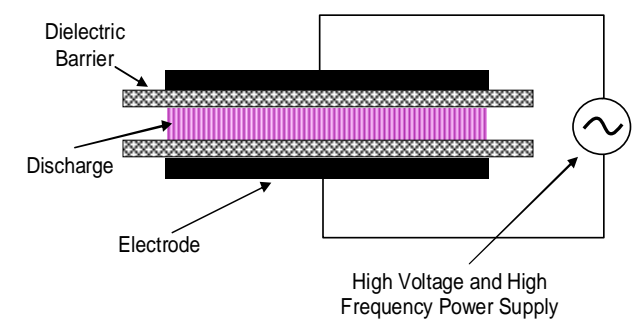

Fig.2 Schematic diagram of parallel plate electrode system at which DBD was obtained at atmospheric pressure.

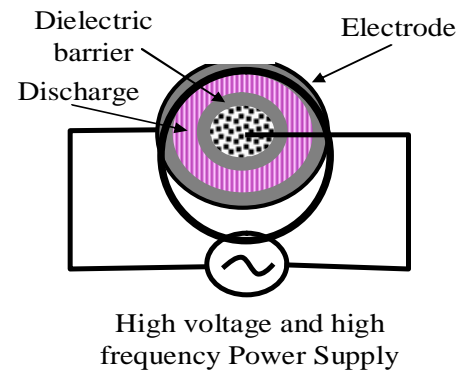

Fig.3 Schematic diagram of annular electrode system at which DBD was obtained at atmospheric pressure.

\section{RESULTS \& DISCUSSION}

Initially, at small applied voltage no discharge was observed between the electrodes. However, on raising the voltage and frequency, a filamentary discharge was observed between inter-electrode gap. To obtain a homogeneous discharge, the voltage and frequency were carefully adjusted. This adjustment tunes the load capacitance to the intrinsic capacitance of the power supply unit. Uniform discharge was observed throughout the interelectrode space only at particular values of voltage and frequency. These values were measured for the three types of electrodes and a comparison has been made. When the voltage across the cylindrical electrodes was about voltage $6.69 \mathrm{kV}$ and frequency $19.19 \mathrm{kHz}$, 
quite uniform discharge was produced throughout length of inter-electrode gap. Under this condition the discharge current was found to be $0.48 \mathrm{~mA}$. Similarly, in the case of parallel plate electrodes, homogeneous discharge throughout entire inter-electrode gap was observed at a voltage of $6.01 \mathrm{kV}$ and frequency $17.75 \mathrm{kHz}$. The discharge current under this condition was found to be $0.55 \mathrm{~mA}$. In the case of annular electrodes, a homogeneous discharge was observed at voltage $5.92 \mathrm{kV}$ and frequency $17.64 \mathrm{kHz}$ and corresponding discharge current was $0.35 \mathrm{~mA}$. During these conditions of homogenous discharge, the apparent power consumed by the cylindrical, parallel plate and annular geometry were $2.38 \mathrm{~W}, 2.26 \mathrm{~W}$ and $1.38 \mathrm{~W}$ respectively. These results are summarized in Table 1. From the table, it is evident that annular electrode system will have better efficiency because of the low power consumption.

Table 1: The voltage, current, frequency and apparent power of most homogeneous discharges in different types of electrode systems.

\begin{tabular}{|c|c|c|c|c|c|}
\hline S.N. & Types of electrode & $\begin{array}{c}\text { Voltage } \\
(\mathrm{kV})\end{array}$ & $\begin{array}{c}\text { Current } \\
(\mathrm{mA})\end{array}$ & $\begin{array}{c}\text { Frequency } \\
(\mathrm{kHz})\end{array}$ & $\begin{array}{c}\text { Apparent } \\
\text { power }(\mathrm{W})\end{array}$ \\
\hline 1. & Cylindrical & 6.69 & 0.48 & 19.19 & 2.38 \\
\hline 2. & Parallel & 6.01 & 0.55 & 17.75 & 2.26 \\
\hline 3. & Annular & 5.92 & 0.35 & 17.64 & 1.38 \\
\hline
\end{tabular}

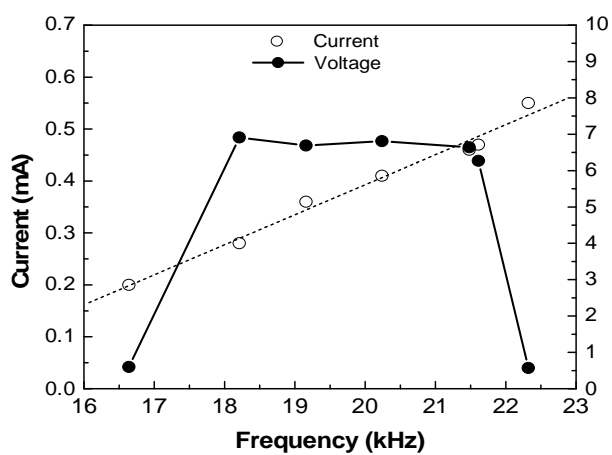

Fig. 4 Cylindrical electrode

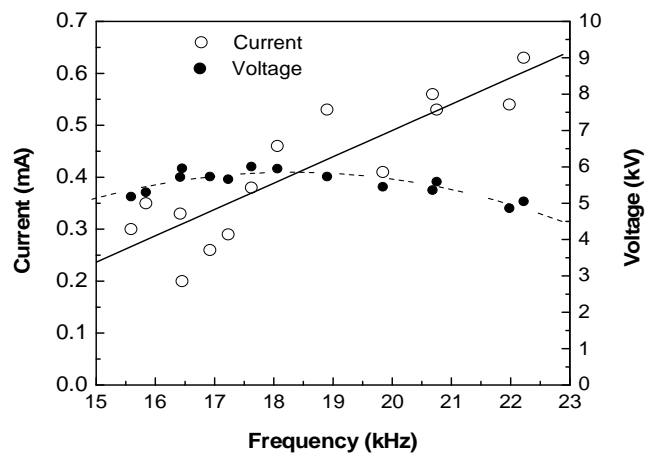

Fig. 5 Parallel plate electrodes

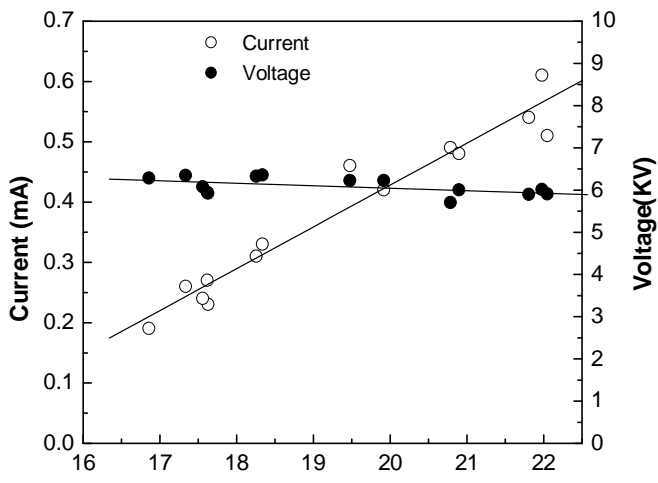

Fig. 6 Annular electrodes 
Figs. 4, 5 and 6 show the plot of discharge current and voltage as the function of frequency of the applied power source in cylindrical, parallel-plate and annular systems respectively. It is observed that the discharge current increases linearly with frequency in all the three configurations. However, the voltage across the gap was found to increase at the beginning and remain unaffected by the frequency up $21 \mathrm{kHz}$ and then decrease with frequency afterwards. It is due to the fact that the voltage across the capacitive load is a function of the ratio of circuit reactance to resistance of the load. We found that this type of dependence of voltage on frequency is prominent in the case of cylindrical electrode and the dependence becomes weaker in the case of planar and annular electrodes. This can be attributed to the difference in volume of discharge between electrodes in the three cases. In the case of a cylindrical electrode, the discharge is in the shape of a thin plane. Hence, the power density is maximum. However, the volume of the air in the gap is more in the other two cases, resulting reduction in power density. The smaller power density may have caused the weaker influence of frequency on the uniformity of discharge. Further investigation with high speed camera would be necessary to confirm this result.

Fig. 7 shows photographs of the discharge during most uniform phase in cylindrical, parallel plates and annular electrodes respectively. However, it was not a glow discharge and consisted of many filaments extending throughout the space between the electrodes.

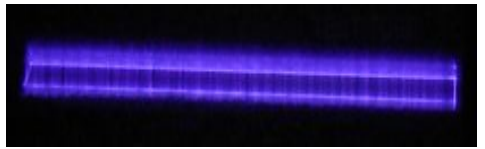

Cylindrical

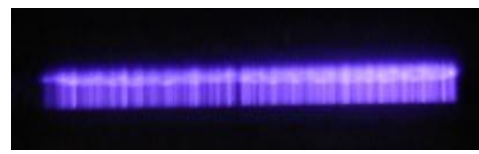

Parallel plate

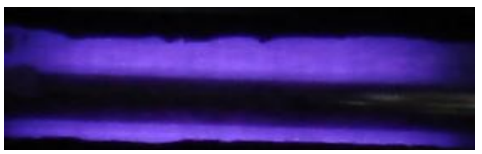

Annular

Fig. 7 Images of discharge in cylindrical, parallel plate and annular electrodes system

An example of effect of DBD on the surface property of a polymer is given in Fig. 8. It shows the image of water drop on the surface of untreated and treated polyethylene (PE) samples. A PE surface was modified with the plasma and the change in hydrophilicity of the surface was investigated. The water contact angle on untreated PE sample was more than $90^{\circ}$ whereas it reduced to less than $40^{\circ}$ after few seconds of treatment in DBD without the loss in its bulk properties.

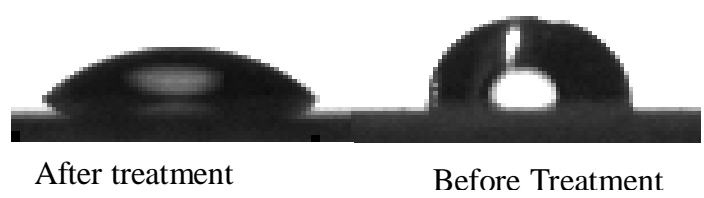

Fig. 8 Images of water drop on untreated and plasma treated polyethylene samples

\section{CONCLUSION}

Atmospheric pressure air discharge was produced by applying $10-30 \mathrm{kHz}, 0-30 \mathrm{kV}$ AC source to three types of electrodes. The homogeneity of the discharge was found to depend strongly on the frequency of the applied power and also on the type of the electrode. The discharge produced in parallel plate electrode was found to be most stable and homogenous. Contact angle measurement on PE treated in the discharge showed that the discharge bears the properties of thermal non-equilibrium plasma. Further investigation about the dependence of the homogeneity of DBD on different parameters such as the nature of dielectric material and the working gas are in progress. 


\section{ACKNOWLEDGEMENT}

The authors would like to thank Prof. C.S. Wong, Physics Department, Faculty of Science, University of Malaya, Kuala Lumpur, Malaysia for his valuable suggestions during the entire period of work. We would also like to thank Dinesh K. Madhup for his technical support related to the electrical measurements.

\section{REFERENCES}

1. Shenton M. J. and Stevens G. C., Wright N. P. and Duan, X., 2001. Chemical-surface modification of polymers using atmospheric pressure nonequilibrium plasmas and comparisons with vacuum plasmas. J. Appl. Phys. Vol. 40, pp.95-109.

2. Wakida T.,1996. Surface modification of fibre and polymeric materials by discharge treatment and its application to textile processing. Indian J. of Fibre and Textile Research.Vol 21, pp. 69-78

3. Kogelschatz U., Eliasson B., and Egli W., 1997. Phemomena in Ionized Gases, XXIII. International conference on Toulouse Invited Papers, pp . C4-47 to C4-66.

4. Tepper J., Lindmayer M. and Juttner B., 2000. Effects of interface between dielectric barrier and electrode on homogeneous barrier discharges at atmospheric pressure. XIII international conference, Scotland, pp.03-08.

5. Kogelschatz U., Eliasson B. and Egli W., 1999, Oxone generators to flat television screens: history and future poltential of dielectric- discharges. Pure Appl. Chem., Vol.71, pp.1819-28.

6. Fridman A., Chirokov A. and Gustol A., 2005. Non-thermal atmospheric pressure discharges. J. Phys. D: Appl. Phys. Vol. 38 pp.R1-24.

7. Hammer T., 1999. Application of plasma technology in environmental techniques. Contrib. Plasma Phys.Vol. 39 pp. 441-62.

8. McAdams R., 2001. Prospects for non thermal atmospheric plasmas for pollution abatement J. Phys. D: Appl. Phys. Vol. 34 2810-21.

9. Bogaerts A., Neyts E., Gijbels and Van Der Mullen J., 2002. Gas discharge plasmas and their applications. Spectrochim, Acta B, Vol. 57, pp. 609-58.

10. Moon S. Y., Choe W., Kang B. K., 2004. Uniform glow discharge plasma source at atmospheric pressure. Appl. Phys. Lett. Vol. 84, pp.188-190.

11. Moisan M., Hubert J., Margpt J., Sauve G., and Zakrzewki Z., 1992. Microwave Discharge: Fundamental and Application, Edited by Ferreira C. M. and Moisan M. (Plenum, New York,), Chep. 1.

12. Park J., Henins I., Hermann H. W., and Selwyn G. S., 2001. "Gas Breakdown in an Atmospheric Pressure RF Capacitive Plasma Source. J. Appl. Phys. Vol. 89, p.15. 
13. Simor M., Rahel J., Vojtek P., Cernak M., and Brablec A., 2002. Atmosphericpressure diffuse coplanar surface discharge for surface treatments. Appl. Phys. Lett. 81, pp. 2716-2718.

14. Moon S. Y., Choe W., and Han J., 2006. Control of radio-frequency atmospheric pressure argon plasma characterize by helium gas mixing. Phys. Of Plasma Vol. 12, pp. 013504.

15. Napartovich A. P., 2001. Overview of Atmospheric pressure discharges producing non-thermal plasma. Plasma and Polymer, Vol 6, pp. 1-14.

16. Massines F., Rabehi A., Descomps P., Gadri R. B., Segur P., and Mayoux C.,1998. Experimental and theroitical study of a glow discharge at atmospheric pressure controlled by dielectric barrier. J. Appl. phys. Vol. 83, pp.. 2950-2957.

17. Jidenko N., Petit M. and Borra J. P., 2006, Electrical characterization of microdischarges produced by dielectric barrier discharge in dry air at atmospheric pressure. J. Phys. D: Appl. Phys. Vol. 39 pp. 281-293. 